\title{
Communicative Figurations of Expertization: DIY_MAKER and Multi-Player Online Gaming (MOG) as Cultures of Amateur Learning
}

\author{
Karsten D. Wolf and Urszula Wudarski
}

\subsection{Introduction: New Cultures of Learning}

With the rise of participatory media over the past two decades, a 'new culture of learning' (Gee 2008; Thomas and Brown 2011) has been described, in which younger people especially develop expertise in different domains outside formal education, vocational training or structured apprenticeships. Following the non-media-related work of Hull and Schultz (2002) on 'literacy out of school', Ito et al. (2009: 17) coined the term 'geeking out' for media-rich informal learning processes, in other words the 'intensive and frequent use of new media, high levels of

K.D. Wolf $(\bowtie) \cdot$ U. Wudarski

ZeMKI, Centre for Media, Communication and Information

Research, University of Bremen, Bremen, Germany

e-mail: wolf@uni-bremen.de

U. Wudarski

e-mail: wudarski@uni-bremen.de

(C) The Author(s) 2018

A. Hepp et al. (eds.), Communicative Figurations, Transforming Communications - Studies in Cross-Media Research, https://doi.org/10.1007/978-3-319-65584-0_6 
specialised knowledge attached to alternative models of status and credibility and a willingness to bend or break social and technological rules' (Horst et al. 2009: 66). Thomas and Brown (2011: 104) argue that geeking out 'promotes intense, autonomous, interest driven learning'. In other words, they describe a new level of autodidactical acquisition of expertise in self-chosen learning domains through everyday practices of advanced media appropriation in times of deep mediatization.

This optimistic description of participatory media supporting selfdirected learning has been challenged by a more general critical assessment of internet participatory culture.

Keen (2007), for instance, argues that amateurs' contributions are of little value in comparison to experts' opinions. Carr (2010) bemoans the loss of deep reading and a lack of focus induced by heavy multitasking, while Lanier (2013) points out the danger of content created for free distribution by users. All of them have strong concerns that participation on the internet is neither quality enhancing nor open to all. The emergence of critical studies of adult learning theories (Brookfield 2005), social media and the information society question (Fuchs 2013; Fuchs and Sandoval 2013) cast further doubts on a possible empowerment of learners. Educational technology itself is not a neutral tool, but may put across an implicit, hidden, political and economical agenda (Selwyn 2013; Fischer and Wolf 2015), skewing the balance from 'learning by doing' back to instruction (Buckingham 2013: 199). Empirical studies also provoke serious doubts that 'geeking out' is an everyday practice accessible to average people, neither able to transcend the digital disparities (Gibbons 2008; Ragnedda and Muschert 2013) nor break up the educational divide (Lane 2009; Friesen and Lowe 2012).

Therefore, it is an open question as to whether a changing media environment in times of deep mediatization opens up informal expertise development for everyone across all learning domains, or if this process has been overrated and is instead only happening in certain domains and for some elite users. To further investigate this contested field of study, we decided to analyze in detail how amateurs appropriate digital media for expertization. This chapter describes our first steps into analyzing similarities and differences between different learning domains taking a figurational approach (Hepp and Hasebrink 2014). 


\subsection{Amateurs' Development of Expertise with Media}

\subsubsection{Development of Expertise}

A central claim of the 'new learning culture' is that learners can autodidactically develop expertise not only on a beginner's but also on an intermediate to high level. While Ericsson (1996) describes expertise solely as superior performance of individuals, Feist (2014) describes expertise as a stepwise model of competence development (novice, initiate, apprentice, journeyman, expert, master). To develop expertise, both intentional learning processes and implicit learning in a stimulating environment is needed to become an expert (Eraut 2000; van de Wiel et al. 2011). In his deliberate practice theory, Ericsson $(2008,2009)$ argues that a certain quality of both practice and experience in a learning domain is needed to achieve true mastery. The type of practice that is most effective is domain-specific; for example, chess players have to study differently from piano players or professional athletes (Ericsson 2006). Van de Wiel et al. (2011: 7ff.) emphasize the importance of professional learning support and specific performance contexts (Gruber et al. 2010). It therefore comes as no surprise that most experts have both been formally trained and therefore had access to teachers or coaches with a planned curriculum, as well as working as professionals for several years or even decades with extensive exposure to implicit learning opportunities in the workplace.

At first sight, these findings speak against the concept of a 'new learning culture' described above. Nevertheless, Mieg (2008) reports on amateurs or laypeople who acquire expertise in the absence of a formal education and certification practice, calling them 'relative' experts. According to Mieg, these 'relative' experts can work on a comparable level to 'professional' experts, or even can become such (Mieg 2008: 3266). This is especially the case for new fields of media-related expertise (Thomas and Brown 2011; Wolf 2012).

\subsubsection{Autodidaxy-Everyday Practices of Self-directed Informal Learning}

'Amateur experts' with no access to formal training environments need to be self-directed or self-organized learners (Ponti 2014; Wheeler 2009). Self-directed learning itself is not a new concept, though. In adult education, Malcolm Knowles describes self-directed learning as 
'a process in which individuals take the initiative with or without the help of others, in diagnosing their learning needs, formulating learning goals, identifying human and material resources for learning, choosing and implementing appropriate learning strategies, and evaluating outcomes' (Knowles 1975: 18). According to Livingstone (2001: 2), 'other forms of intentional learning in which we engage either individually or collectively without direct reliance on a teacher/mentor and an externally organized curriculum can be termed self-directed or collective informal learning'. Informal learning plays a very large part in adults' process of lifelong learning, both in professional and private contexts (Illich 1971; Sargant 1991, 1993; Marsick and Watkins 2001; Drotner 2009; Marsick et al. 2011).

Significant self-directed learning can be described as a learning project, which Tough (1971: 1) defines as 'a major, highly deliberate effort to gain certain knowledge and skill (or to change in some other way)', consisting of several intentional learning episodes which add up to at least seven hours. In a fast changing 'knowledge society', both the necessity for self-directed informal learning has increased (Livingstone 1999; Hungerland and Overwien 2004), and the availability of resources such as digitized, networked and mobile media has grown, forcing a 'mediatic turn' of informal learning options (Tully 2008; Friesen and Hug 2009: 79; Hartung 2010) with 'digital media as transformative resources of learning' (Drotner 2009:16).

In his literature review, Candy (1991) argued that a considerable amount of scientific discussion on 'self-directed learning' revolves around the support or execution within formal instructional systems. To differentiate self-directed learning outside formal environments, he proposes the term 'autodidaxy' as educational endeavours pursued in non-institutional, 'natural societal settings' (Candy 1991: 404). These learning processes can be intentionally planned by the learners (intentional autodidactical learning) or incidentally happen while solving problems (incidental autodidactical learning; Simons 2000: 28). These can be combined.

Candy (2004: 51) emphasizes that with access to digital media the difference between informal and formal settings becomes more of a continuum than a dichotomy, because materials and courses intended for more formal learning can be integrated into intentional self-directed learning. Finally, the autodidactical development of expertise must not only be understood as some kind of accumulative learning, in which to 
gradually build up knowledge and skills, but also as processes leading to a potential creation of 'new figures of world- and self-relation' (Koller 2011: 377).

\subsubsection{Appropriation of Media to Develop Expertise}

While the field of expertise research is firmly established, especially in competitive domains such as sports, playing chess and musical instruments, there is nearly no research on the role of (instructional/learning/ communication/digital) media in processes of expertise acquisition (for an absence of discussion of the role of media see Boud and Garrick 1999; Ericsson et al. 2006; Dochy et al. 2012). Even the research on deliberate practice discusses the role of learning media-if at all-only within formal learning settings, such as the use of simulations in medical education (McGaghie et al 2011).

The role of media in informal learning processes to develop expertise has been mainly described or touched upon outside expertise research in five contexts central for our research project:

1. Sociocultural studies focusing on everyday cognition and practices of informal learning (Rogoff and Lave 1984; Lave and Wenger 1991; Rogoff 2008) have examined, 'how people participate in sociocultural activity and how they change their participation' to de-mystify 'the processes of learning and development' (Rogoff 2008: 71). For example, Jean Lave examined cognition and learning processes in the practice of cooking (Lave 1988) and sewing (Lave 2011). Extending this work, especially into professional workplace contexts, Etienne Wenger has analyzed the appropriation of online media in communities of practice $(\mathrm{CoP})$ and has developed a typology of social software tools that can enhance informal learning within CoP (Wenger 2001; Wenger et al. 2009; Wolf 2006). In recent ethnographical analysis of hybrid learning communities, Nalita James and Hugh Busher (2013: 205) describe a 'mediascape', but do not analyze individual processes of media appropriation for learning.

2. In media research, Axel Bruns (2008) has coined the term produsage, meaning a process where users become producers of shared knowledge in online networks. While not discussing learning or expertise in a deeper way, Bruns describes the mediatized 
contribution of amateurs to expert knowledge (Bruns 2011). In 'fandom' research we can find descriptions of fan-group members as self-directed learners appropriating media such as forums, blogs, video portals and wikis (Hills 2002; Jenkins 2006; Jenkins et al. 2009; Ito et al. 2012; Jenkins et al. 2015).

3. Youth research in sociology has a long tradition in research of media appropriation (Hasebrink and Lampert 2011; Kammerl 2011). Especially youth scenes are described as non-professional learning communities, in which members attain competences in 'careers' (Schnoor and Pfadenhauer 2009: 302ff.). This research focuses more on phases and positions within scenes (Lachmann 1988) than on individual media usage. Studies about the role of media in scenes so far investigate single communication platforms such as forums or social networking sites (Jörissen 2007; Hugger 2009). The 'media convergence study' in Germany (Schorb et al. 2013) has analyzed young people's searching for information across media forms such as the internet, TV, journals or books (Wagner et al. 2012; Gebel et al. 2014), but not processes of goaloriented learning to build up expertise.

4. In media education research, there is a growing interest in the appropriation of media to understand (young) learners' selfdirected learning (Drotner 2008; Wolf 2012; Ranieri and Pachler 2014), but also how to use identified principles of informal learning, such as Kurt Squire's (2011) discussion of 'games for learning' or Ito et al.'s concept of 'connected learning' (Ito et al. 2013), for formal or non-formal education programmes. Learners' informal use of online and social media for learning has mostly been studied in higher education settings (Bernhardt and Wolf 2012; ZawackiRichter 2015). This line of research clusters usage-types such as advanced media users and recreational media users, but does not analyze individual development of expertise.

5. Research on personal learning environments (Downes 2006; Attwell 2007; Fiedler and Väljataga 2013) as well as cMOOCs (Siemens 2005; Kop et al. 2011) focuses on processes such as aggregation, remixing, repurposing and feeding forward, where learners actively appropriate social media to support their own learning processes. A central question in informal learning theory is how learners and their 'ecologies of learning options' (Moravec 2013: 81) can compensate for the lack of a formal learning 
environment. According to Vygotsky, a learner can develop his or her expertise only to an individual maximum level of independent performance (Vygotsky 1980). To widen the 'zone of proximal development', learners need access to a 'more knowledgeable other' (MKO). While Vygotsky thought of the MKO as a human actor, Attwell argues that 'the MKO can also be viewed as a learning object or social software which embodies and mediates learning at higher levels of knowledge about the topic being learned than the learner presently possesses' (Attwell 2011: 89; see also Peña-López 2013). Luckin (2010) has developed an ecology of resources framework extending this understanding of both humans and learning resources as MKOs in self-managed learning settings.

To sum up, a changing media environment seems to provide new opportunities for amateur learners to develop expertise outside formal educational systems and eventually even to become professionals, but it is very unclear what role media repertoires play in individual learning processes and what impact they have on amateurs' (dis-)empowerment and segmentation/participation.

\subsection{Research Question and Methods of Data Collection}

In this chapter, we want to explore and study amateurs' expertization in a changing media environment. To do this, we are trying to interlace media studies with learning and education studies (Drotner and Erstad 2014). Hepp and Hasebrink (2014: 250) propose communicative figurations as an approach for a 'practical, transmedial analysis of the changing communicative construction of mediated cultures'. Communicative figurations can be described as 'patterns of processes of communicative interweaving that exist across various media and have a "frame of relevance that orients communicative action"' (Hepp 2013: 9).

In the context of informal 'learning projects' (Tough 1971), individual learners become interested in a specific learning domain, which acts as a common frame of relevance. To develop their expertise, learners use certain practices of communication within specific constellations of actors. Practices of communication are complex patterns of communication forms using a subset of the individual's media repertoire (the sum of all media they are using). While communicating, learners eventually 
discover new media forms, which they may integrate into their own repertoire. The individuals' communicative practices of learning both shape and are shaped by a specific communicative figuration. Apart from other factors such as different capital sorts (Ziegler 2012), the learners' communicative repertoire affects their level of (possible) participation in a domain's communicative figuration of expertization.

To reconstruct communicative figurations of expertise development within and across different learning domains, it is advisable to do multisite studies. These are especially necessary to discover disconnected parts of a figuration's media ensemble and communication practices. For example, in the learning domain of knitting (a DIY_MAKER subdomain) we identified some older learners who were exclusively using non-digital media such as printed journals and books, advice from family members and friends in private environments or from shop owners in knitting stores, while younger learners in particular often became exposed to knitting on YouTube and did not use any analogue media for their expertization in knitting at all. While there is a vast online culture of knitting, it was important to look for these other analogue places to discover important offline parts of a figuration. Furthermore, when we talked to knitters in knitting stores or at DIY fairs, we also found learners who were using online media solely passively, printing out the information and bringing it into their offline knitting groups. And some younger learners who were active on social media websites such as Pinterest, YouTube and Etsy were actively seeking the knowledge of older 'nonliner' knitters as well as old knitting books, and transferring this knowledge into their online tutorial blogs and videos.

We therefore chose three empirical data access methods for this study: (1) interviews with learners; (2) participant observations within different learning settings; (3) netnographic analysis of learning collectives.

Interviews with learners: the learning practices and media repertoires of learners span from reading analogue media such as printed books and journals or non-networked digital media such as ebooks and pdfs up to online social media sites. Sometimes they participate actively and leave (public) digital traces such as comments, blog entries or YouTube tutorials; sometimes they just read and collect information from websites and forums, operating 'below the radar'. Therefore, interviews are a central data collection method to reconstruct the breadth of learners' communicative practices (Klein, Walter, and Schimank in this volume). 
Participant observations: often learning is happening less consciously while solving problems, and learners do not consider their actions to be part of learning, nor do they realize or remember their media use. For example, in our case study of 'bike gearheads', shared workshops or skate parks were very important places for face-to-face learning communication. Moreover, while a lot of bike gearheads were very critical about social media in their interviews, in our observations they were constantly watching and reposting interesting YouTube videos and links to Facebook to share information about new gear, as well as commenting on other's posts.

Netnographic analysis of learning collectives and individuals: traces of learning communication can be found on the internet for every domain of interest. Individuals document their problem-solving processes online, make them searchable for other learners and help each other ('mediatized learning collectives'; Wolf and Breiter 2014). Starting from systematic internet searches and leads from interviews, large online parts of the figuration's shared media ensemble as well as actor constellations can be reconstructed.

Other possible ways of data collection which were not part of this study but which will be considered for further studies are: (1) online surveys in learning collectivities; (2) learning diaries and learning logging; (3) data scraping for both quantitative network analysis and critical discourse analysis.

\subsection{Selection of Learning Domains}

Thomas and Brown (2011) suggest that in particular new learning domains with no established formal educational structures are open for a 'new culture of learning'. In this study, we therefore selected two emerging learning domain clusters with a large proportion of autodidactical amateur learners and a possible social openness to allow for a more diverse participation.

Multiplayer Online Gaming (MOG): MOG is for most players a recreational (learning) interest. While a professional e-sports scene has been established, most players are hobbyists, and as yet there is no real formal system for professionalization in MOG. MOG encompasses different genres such as First Person Shooters (FPS; e.g. Counter Strike), Massive Open Online Roleplaying Games (MMORPG; e.g. World of Warcraft), Real Time Strategy Games (RTS; e.g. Starcraft), Mobile MOGs 
(e.g. Clash of Clans) or Multiplayer Online Battle Arenas (MOBA; e.g. DotA2). Playing MOG is a broadly established hobby. Popular MOG-franchises such as Call of Duty sell 30 million copies worldwide (D'Angelo 2016). In Germany, 34\% of all teens aged 12-19 play online games daily or several times a week (JIM 2015), although there is a large gender effect, as genres such as FPS are played by approximately $80 \%$ or more male players (Yee 2017).

DIY_MAKER: a resurgence of the Do It Yourself movement has resulted in a growing interest of amateurs not only in the crafts, but also in involvement as an artist or creator (Spencer 2008). DIY encompasses a rich diversity of subcultures ranging from feminist craftism (Greer 2014), environmental conscious upcycling (Smith 2010), anti-capitalist bicycle cooperatives and subculture artists to political-neutral hobbyists such as home improvement and apartment therapy, or commercially oriented self-employed crafters selling their products on DIY e-commerce platforms. The Maker culture can be understood as a kind of technology-based extension of DIY culture (JBushnell on Wikipedia 2010), in which $3 \mathrm{D}$ printers and the physical-computing platform Arduino especially have made hardware development more accessible for amateurs. As there are many connections between DIY and Maker practices (Tanenbaum et al. 2013), we have chosen to use an underscore gap in DIY_MAKER in our study to emphasize the existing overlaps.

A main distinction between the two learning-domain clusters is the natural inclination of MOG learners to use computers/digital media, because they already use them to play games, while in DIY_MAKER learners are often in a manual process of crafting and making, away from their computing devices. Another difference is that MOG developed in parallel to internet technology and makes heavy use of it, while DIY_ MAKER is a new chapter in the century-old history of crafts. Finally, the MAKER movement sits between computer-centred hobbies such as MOG and analogue-focused creation processes of DIY.

As part of the DIY_MAKER complex, we studied bike gearheads in trending bike activities such as bike messaging, dirtbiking and BMX; 3D printing enthusiasts; knitting, tailoring and upcycling crafters; and vegan baking. As part of the MOG complex, we studied First Person Shooter players, Multiplayer Online Battle Arena players; and MMORPG players. In total, we have conducted 42 interviews, collected field notes from participative observations in nine offline sites and studied online learning 
collectives on more than 40 websites and social media platforms, such as Facebook, Twitter, Instagram and YouTube.

In Table 6.1 the research sites are described in detail.

\subsection{Differences in Figurations Between Learning DOMAINS}

Building upon the analysis of individual communication repertoires, media biographies, observations of practices and online activities, this section describes the main aspects and differences of the two learning domains' communicative figurations of learning.

For a conceptual overview, Fig. 6.1 shows schematic media repertoires of five individuals. All five media repertoires are subsets of the current media environment, which is the sum of all media today. A learning domain's media ensemble (LDME) is formed by all individuals' media usage for learning communication within the domain. In reality, thousands or even millions of individuals shape an LDME. Individuals' media repertoires also include other types of media usage that are not part of the

Table 6.1 Description of research sites for data collection

\begin{tabular}{lll}
\hline Interviews & & \\
Domain & Sub-domain & Number of Interview Partners \\
DIY & Trending Bike Activities & 13 \\
DIY & 3D Printing Enthusiast & 2 \\
DIY & Knitting/Upcycling & 5 \\
DIY & Cooking/Baking & 5 \\
MOG $^{\text {a }}$ & FPS & 11 \\
MOG $^{\text {a }}$ & MOBA & 3 \\
MOG & MMORPG & 3 \\
Observations & & \\
Domain & Sub-domain & Number of Sites/Visits \\
DIY & Open Workshops & 2 \\
DIY & Fablabs & 2 \\
DIY & Knitting Shops & 1 \\
MOG & E-sports Events & 2 \\
MOG & Gaming house & 2
\end{tabular}

Data collection was done by Urszula Wudarski, Karsten D. Wolf, Burcin Nar, Julien Eissing, Sabine Schaaf, Carina Lohfeld, Katharina Ellmers, Freya Kuhn, Lilith Wilkening, Svenja Gottschalk, Michael Berndt, Kerstin Kreis, and Hilka Neunaber ${ }^{\mathrm{a}}$ only male participants 
specific LDME (cases A, B, C, D), such as watching movies in a cinema. Empirically, we have so far been unable to find individual learners with a repertoire smaller than an ensemble (hypothetical case E). While an individual learner's learning specific media repertoire (LSMR) - the subset of an individual learner's media repertoire used in a learning domainin most cases only covers a part of a LDME (e.g. a learner using only printed DIY journals and not much else), non-learning-centred media usage outside the LDME was always present, such as watching the news on TV or reading books as a pastime. Compared to the real size of individual's media repertoires and the encompassing media environment, the shown LDME is often much smaller in relation.

Empirically, we rarely found LSMR with more than ten media types, while learners' complete media repertoire were much larger. Case D shows a somewhat common situation, where a specific learner does use a specific media such as WhatsApp in other communicative contexts (therefore it is a part of his or her media repertoire), but not within the learning domain (marked as a white 'non-usage' spot in Fig. 6.1). Nevertheless, other learners use it commonly for learning, so that it becomes part of the LDME. Mainstream communication platforms in particular, such as Facebook, Twitter, WhatsApp or Instagram, are often used from nearly anybody in a certain age range, but not necessarily for informal learning within the learning domain.

\section{media environment}

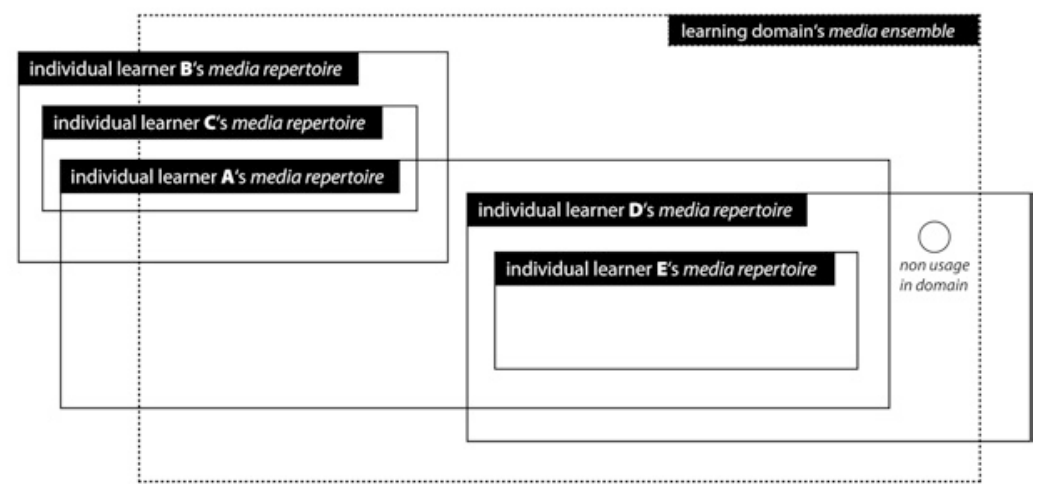

Fig. 6.1 Schematic view of media environment, learning domain's media ensemble and individual learners' media repertoires 
Typical for empirical maps of LDME is the clustering of media repertoires. Within a media ensemble, there will be larger groups of individuals with similar media usage, and these clusters do not necessarily overlap (cluster $\mathrm{B}+\mathrm{C}$; cluster $\mathrm{D}+\mathrm{E}$ ). Some individuals connect these clusters (case A), either by sourcing both clusters for individual deeper knowledge or by bridging in the form of taking knowledge from one communicative learning cluster and sharing it in another cluster.

In our research of individuals' media repertoires, we were interested not only in what media they were using, but how they used media for what (communicative practices). One thus has to add a dimension of communicative activity type. As a first simple analytical step, one can differentiate between consumptive and productive usage of media, such as reading versus posting tweets on Twitter, or reading versus editing Wiki articles. Within media ensembles of learning, these types of activity can be much more differentiated. For example, writing a blog can be a straightforward posting of blog articles, or include rich interactions with other bloggers and readers. Even with the same set of media, different clusters can be identified because of different sets of communicative activity.

Obviously, both DIY_MAKER and MOG are huge domains and encompass divergent subcultures of learning. In a first step, both domains' communicative figurations of learning will be described and compared with each other on a high aggregation level. In a second step, we explore differences within sub-domains.

\subsubsection{Media Ensembles and Communicative Practices of Learning}

We can distinguish four basic types of communication (Krotz 2007; Hepp 2013): direct communication, which happens in a co-present context; reciprocal media communication, with separation of contexts in a synchronous or asynchronous way, of which both are oriented to specific others in a dialogic mode of communication; produced media communication, which is a monologic mode of communication oriented to an indefinite potential number of addressees; and finally, virtualized media communication, which is a form of interlogical communication, where human-made algorithms simulate communicative processes.

In the case of MOG, most learning happens in reciprocal media communication. Players chat either synchronously via in-game text or audio chats, or use external chat systems such as TeamSpeak; or asynchronously use forums for discussing the 'meta game', which is a deep analysis of 
the game mechanics, often impacted by game patches. Player interaction within the game by acting out ways to do things is also an important element of reciprocal, virtual embodied communication. All levels of learners are intensive users of reciprocal communication channels, sometimes even outside the game. For instance, we observed clan members using mobile audio chat apps such as TeamSpeak on their smartphones to listen constantly to a clan's conversation outside the gaming context, for example when they went to a supermarket to buy supplies. Produced media communication such as frequently asked questions (FAQs), Walkthroughs, Let's-Play-Videos or Twitch.tv-Streaming are especially important for beginners to mid-level players. In contrast, direct communication is only important in competitive e-sports tournament settings, when teams train and play in co-presence, although even then audio chat programs (reciprocal media) are used.

Additionally, MOGs are a domain with rich virtualized media communication, mostly in the form of Non-Player Characters (NPCs; computer controlled players) and Bots (computer controlled enemies). NPCs often suggest tasks based on the players' current abilities. This helps to accelerate the learning curve of players. Bots are important training partners for deliberate practice. Again, this communication becomes less important with higher levels of expertise.

In comparison, DIY_MAKER learners are much more involved in direct communication within co-present contexts, such as in co-workspaces, workshops, fairs, shops or private homes. The physical (hardware) nature of objects with a need to feel and show fosters such direct communication. Produced communication is also very important in form of written, visual or audio-visual tutorials on blogs, Instagram, Facebook, tutorial websites or YouTube. There is also a depth of asynchronous reciprocal media communication in forums or comment systems. There is no virtualized media communication.

Figure 6.2 shows a high level comparison of media ensembles between MOG and DIY_MAKER. While mainstream media such as Facebook or YouTube are part of both ensembles, each learning domain has very specific media types not used in the other. One reason for this is the different needs and affordances of the domains' skill sets. In DIY_ MAKER, it is common to search for creative inspiration for new products to make, so social (image) sharing becomes very popular; hence Instagram and Pinterest are very important parts of media ensembles. In MOG, watching performance and following live commentary is an 


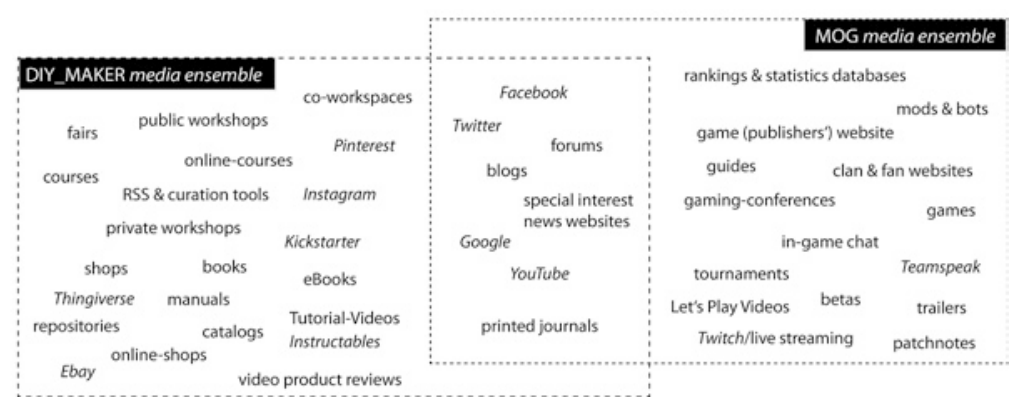

Fig. 6.2 Comparison between two learning domains' media ensembles (DIY_ MAKER versus MOG)

important part of skill building, so live streams of gaming on Twitch or YouTube Live generate thousands of views. While there is a strong trend to visual media such as video or photographs, very specialized knowledge topics are still being discussed in written form on forums.

Within each of the sub-domains, there are further layers of details and differentiation. For example, within 'gearheads in trending bike activities', the relative age and maturity of a learning domain plays a role for its media ensemble. While BMX is a well established 'old school' activity with a rich body of mediatized knowledge bases, Dirtbike is more of an upcoming activity, which has yet to be systematized. Therefore, it is nearly impossible for semi-pro and amateur learners in BMX to create interesting tutorial videos. Everything has been done and the production value is extremely high ('better than I can do it'), therefore participation in sharing videos is lower than in Dirtbike.

\subsubsection{Constellation of Actors}

Actors are manifold in communicative figurations of informal learning: learners as individual actors, groups of problem-solving learners as collective actors, corporate actors such as publishers and commercial training providers.

In the MOG constellation of actors, most games are produced by commercial companies. MOG represents a huge market, but also require expensive resources such as servers. Even successful community 'mods' 
(modifications of a game) have been 'sucked' into commercial products, such as popular MOBA Defense of the Ancients (DoTA) or FPS Counter Strike. Because of their competitive nature, MOGs were especially fitting to be established as an e-sport with high prize money for tournaments. Together with both professional and amateur press, this formed a strong commercialization arena of MOG, further increased by lifestyle brands acting as sponsors.

A second arena is the meta-game discourse. Here, all game mechanics are discussed and contested. Game developers are at the centre of both commercialization and meta-game. Their task is to make games attractive both from a gamer's (enjoyment) and publisher's (profit) perspective. At the centre of the learning arena are both serious/competitive amateur gamers, who often share their knowledge with each other, and commercially oriented Twitch live streamers and Let's Players on YouTube. Casual and hobby gamers are mostly playing and not analyzing. With higher knowledge of the meta-game, actors become more influential on the meta-game discourse, eventually directing the development of patches and future games (Fig. 6.3).

While Massive Multiplayer Online Games (MMORPG) can be played within larger groups such as clans and raid groups against NPCs and other players, in most cases MOGs are played in smaller teams, such as in groups of five (MOBA) or even singly against other individuals (arcade FPS). The competitive nature and the game mechanisms induce

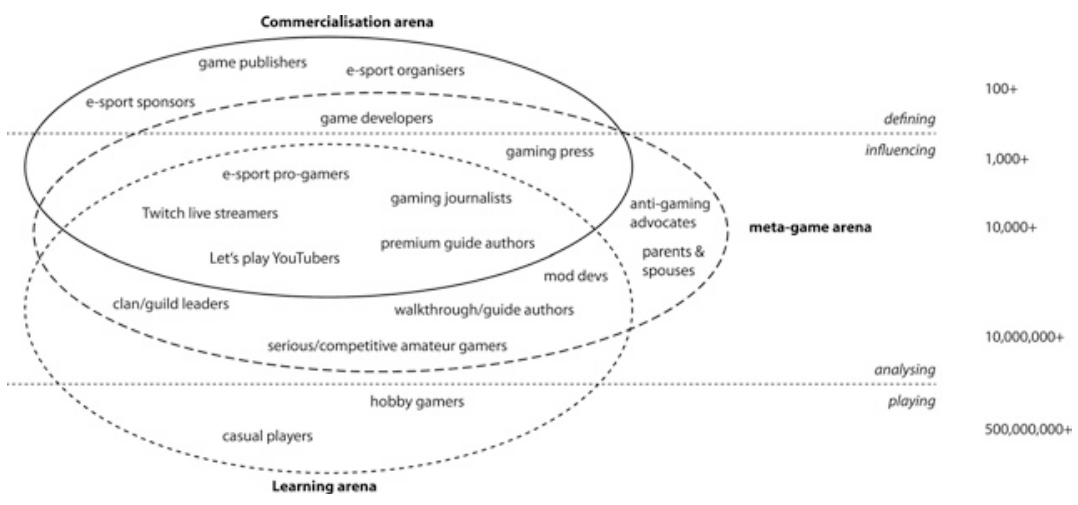

Fig. 6.3 Constellation of actors for learning domain Multiplayer Online Gaming 
a necessary command structure and therefore a hierarchy within groups of players. Furthermore. the performance level becomes very visible and quantifiable via ladder systems, trophies and other ranking systems. Progamers can become 'stars' with a fan following.

Because most of the learning happens within games, the learning constellation of actors is focused on smaller groups of people. People are dependent on one another to work as a team. If the competence levels of players are too diverse, they often don't stay connected. For beginners or newbies, it is obvious that other players are on a higher expertise level. Outside interpersonal communication in clans or other groups, only few experts provide their knowledge actively in produced media for others to follow, such as tutorials and Let'sPlay videos on YouTube or in live streams on Twitch. Much of the reciprocal communication on meta-game issues happens in blogs or forums, as well as collaboratively in FAQs and Walkthroughs.

In our interviews with semi-pro FPS gamers, it became clear that learners move easily between different sets of actor constellations: they played Real Time Strategy Games alone against other anonymous players for relaxation, mostly in a learning-by-doing style; with their spouses they played puzzle games or MMORPG in a co-present setting, helping each other in direct communication; with family members and friends they played 'accessible' FPS such as Halo on their video game console, sharing their deep knowledge with their co-players as an expert; but in their Battlefield Clan they practised in a commando structure, led by more experienced players.

In e-sports settings such as professional MOBA teams we observed an even higher specialization. Analysts were profiling other teams, creating video analyses of other players, and coaches were setting up training routines for the players based on these profiles.

In comparison, in DIY_MAKER we find a much more egalitarian constellation of actors, as there are no ranking systems or other competitive elements. For example, a vegan food blogging expert stated that she learned a lot from the comments and ideas of her readers, who often transformed her recipes and shared new knowledge. Again, we found a social arena of commercialization, although it is smaller in volume. While the computer game industry is huge (e.g. computer game publisher Electronic Arts made 4.52 billion dollars in revenue in 2015), important MAKER projects such as Arduino/Genuino are open source, 


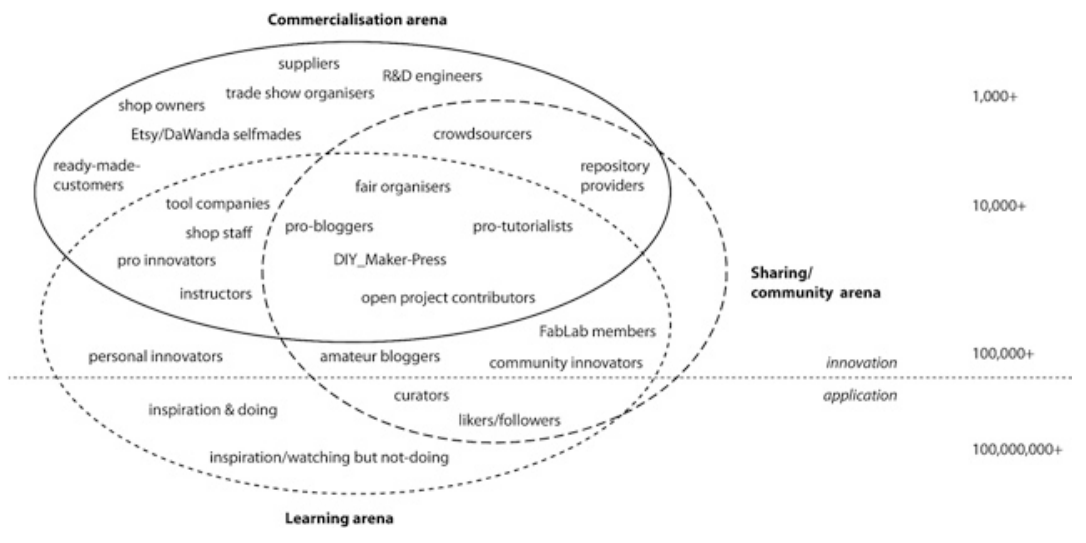

Fig. 6.4 Constellation of actors for learning domain DIY_MAKER

grassroots projects. As there are many different interests and projects in DIY_MAKER, companies tend to be smaller and less dominant.

A very important social arena in the learning constellation of DIY MAKER actors is sharing and community, because most innovation and learning resources are created collaboratively, so even the commercial DIY_MAKER press is participating in these sharing activities (Fig. 6.4).

\subsection{Conclusion}

Taking a figurational perspective on learning domains, we could show that both maps of media ensembles and constellation of actors are helping us to describe the complexity of communicative practices and the role of media in two exemplary learning domains. Several things can be learned:

Media ensembles of learning are highly dependent on the learning domain, because a domain consists of specific knowledge and skills, which demand different forms of media. For example, in 3D printing, objects are often described in STL (STereoLithography) files, which can be shared in file repositories such as Thingiverse. These files open up information about the construction of the models and are a very important resource for further learning. For MOG players, on the other hand, information about new successful strategies cannot be shared in repositories but instead more easily on YouTube or Twitch. 
In the analysis of the constellation of actors, we can identify different social arenas of discourse. Within both learning domains, there are direct intersections between commercialization and learning arenas: amateurs trying to earn some money by providing learning resources; learners turned into possible customers of companies; or companies trying to support the development of their customers' expertise so they become interested in more advanced commercial offerings.

In DIY_MAKER, there exists a strong sharing/community arena, which acts as a counterforce to the commercialization arena to support self-development instead of customer education. In MOG, we can find a stronger commercialization arena. Tensions between 'gaming industry', 'cultural values of games' and 'fun' are negotiated in the meta-game arena by developers, journalists, pro and amateur gamers. One could argue, furthermore, that the commercialization arena and the learning arena together form a competition arena, which is further moulding the learning aspiration of amateur learners.

Empirical reconstructions of learning domains' communicative figurations have proven to be very promising for the further analysis of informal learning in times of deep mediatization.

\section{REFERENCES}

Attwell, Graham. 2007. Personal learning environments-the future of eLearning? Elearning papers 2 (1): 1-8.

Attwell, Graham. 2011. The future learning environments. In IATEL: Interdisciplinary approaches to technology-enhanced learning, ed. Max Mühlhäuser, Werner Sesink, Andreas Kaminski, and Jürgen Steimle, 75-94. Münster, New York, München, and Berlin: Waxmann.

Bernhardt, Thomas, and Karsten D. Wolf. 2012. Akzeptanz und Nutzungsintensität von Blogs als Lernmedium in Onlinekursen [Acceptance and usage of blogs in online courses]. In Digitale Medien. Werkzenge für exzellente Forschung und Lehre [Digital media. Tools for excellent research and teaching], eds. Gottfried Csanyi, Franz Reichl, and Andreas Steiner, 141152. Münster: Waxmann.

Boud, David, and John Garrick, J. 1999. Understanding learning at work. London and New York: Psychology Press.

Brookfield, Stephen D. 2005. The power of critical theory for adult learning and teaching. Maidenhead: Open University Press.

Bruns, A. 2008. Blogs, Wikipedia, second life, and beyond: From production to produsage. Frankfurt am Main: Peter Lang. 
Bruns, Axel. 2011. Beyond difference. In Digital difference. Perspective on online learning. Educational futures: Rethinking theory and practice, eds. Ray Land and Siân Bayne, 133-144. Rotterdam: Sense Publishers.

Buckingham, David. 2013. Media education: Literacy, learning and contemporary culture. Chichester: Wiley.

Candy, Philip C. 1991. Self-direction for lifelong learning: A comprehensive guide to theory and practice. Chichester: Wiley.

Candy, Philip C. 2004. Linking thinking: Self-directed learning in the digital age. PANDORA electronic collection. Canberra: Dept. of Education, Science and Training.

Carr, Nicholas. G. 2010. The shallows: What the internet is doing to our brains. New York: W.W. Norton.

D’Angelo, William. 2016. “Call of Duty: Black Ops 3 Tops an Estimated 25M Units Sold Worldwide at Retail." VGChartz. http://www.vgchartz.com/ article /266166/call-of-duty-black-ops-3-tops-an-estimated-25m-units-soldworldwide-at-retail/. Accessed 23 Aug 2017.

Dochy, Filip, David Gijbels, Mien Segers, and Piet van den Bossche. 2012. Theories of learning for the workplace: Building blocks for training and professional development programs. Abingdon, NY: Routledge.

Downes, Stephen. 2006. Learning networks and connective knowledge. Collective intelligence and elearning 20: 1-26.

Drotner, Kirsten. 2008. Leisure is hard work: Digital practices and future competences. In Youth, identity, and digital media, ed. David Buckingham, 187211. Cambridge MA: Heinemann (The MacArthur Foundation series on digital media and learning).

Drotner, Kirsten. 2009. Informal learning and digital media: Perceptions, practices and perspectives. In Informal learning and digital media, ed. Kirsten Drotner, Hans S. Jensen, and Kim C. Schrøder, 10-28. Cambridge: Cambridge Scholars Publishing.

Drotner, Kirsten, and Ola Erstad. 2014. Inclusive media literacies: Interlacing media studies and education studies. International Journal of Learning and Media 4 (2): 19-34.

Eraut, Michael. 2000. Non-formal learning and tacit knowledge in professional work. British Journal of Educational Psychology 70 (1): 113-136.

Ericsson, Karl A. 1996. The acquisition of expert performance: An introduction to some of the issues. In The road to excellence: The acquisition of expert performance in the arts and sciences, sports, and games, ed. Karl A. Ericsson, 1-50. Hillsdale, NJ: Lawrence Erlbaum Associates.

Ericsson, K.A. 2006. The influence of experience and deliberate practice on the development of superior expert performance. In The Cambridge handbook of expertise and expert performance, eds. Karl A. Ericsson, Neil Charness, Paul J. Feltovich, and Robert R. Hoffman, 683-703. Cambridge: Cambridge University Press. 
Ericsson, Karl A. 2008. Deliberate practice and acquisition of expert performance: A general overview. Academic Emergency Medicine 15 (11): 988-994.

Ericsson, K.A. 2009. Development of Professional Expertise: Toward Measurement of Expert Performance and Design of Optimal Learning Environments. Cambridge: Cambridge University Press.

Feist, Gregory J. 2014. Psychometric studies of scientific talent and eminence. In The Wiley handbook of genius, ed. Dean K. Simonton, 62-86. Malden, Oxford, and Chichester: Wiley.

Fiedler, Sebastian H.D., and Terje Väljataga. 2013. Personal learning environments: A conceptual landscape revisited. eLearning Papers 35: 1-16.

Fischer, Gerhard, and Karsten D. Wolf. 2015. What can residential, researchbased universities learn about their core competencies from MOOCs (Massive Open Online Courses)? In Teaching is touching the future. Academic teaching within and across disciplines, eds. Heidi Schelhowe, Melanie Schaumburg, and Judith Jasper, 65-75. Bielefeld: UniversitätsVerlagWebler.

Friesen, Norm, and Theo Hug. 2009. The mediatic turn: Exploring concepts for media pedagogy. In Mediatization: Concept, changes, consequences, ed. Knut Lundby, 63-83. Frankfurt am Main: Lang.

Friesen, Norm, and Shannon Lowe. 2012. The questionable promise of social media for education: Connective learning and the commercial imperative. Journal of Computer Assisted learning 28 (3): 183-194.

Fuchs, Christian. 2013. Social media: A critical introduction. Los Angeles: Sage.

Fuchs, Christian, and Marisol Sandoval. 2013. Critique, social media and the information society. New York: Routledge.

Gebel, Christa, Nadine Jünger, and Ulrike Wagner. 2014. Informations- und engagementbezogenes Medienhandeln von Jugendlichen [Adolescents' media activitiy regarding information and engagement]. In Jugendliche und die Aneignung politischer Information in Online-Medien [Adolescents and appropriation of political information in online media], ed. Ulrike Wagner, and Christa Gebel, 53-136. Wiesbaden: Springer Fachmedien.

Gee, James P. 2008. What video games have to teach us about learning and literacy. New York: St. Martin's Press.

Gibbons, Michael. C. 2008. Digital disparities. In eHealth solutions for healthcare disparities, ed. Michael C. Gibbons, 66-71. New York: Springer.

Greer, Betsy. 2014. Craftivism: The art of craft and activism. Vancouver: Arsenal Pulp Press.

Gruber, Hans, Petra Jansen, Joerg Marienhagen, and Eckart Altenmueller. 2010. Adaptations during the acquisition of expertise. Talent Development o Excellence 2 (1): 3-15.

Hasebrink, Uwe, and Claudia Lampert. 2011. Kinder und Jugendliche im Web 2.0-Befunde, Chancen und Risiken [Children and adolescents in Web 2.0]. Aus Politik und Zeitgeschichte 3: 3-17. 
Hartung, Anja. 2010. Medien als Orte informellen Lernens? [Media as informal learning spaces?]. In Soziale Arbeit und Medien [Social work and media], ed. Georg Cleppien, and Ulrike Lerche, 71-83. Wiesbaden: VS Verlag für Sozialwissenschaften.

Hepp, Andreas. 2013. The communicative figurations of mediatized worlds: Mediatization research in times of the 'mediation of everything'. European Journal of Communication 28 (6): 615-629.

Hepp, Andreas, and Uwe Hasebrink. 2014. Human interaction and communicative figurations. The transformation of mediatized cultures and societies. In Mediatization of communication, ed. Knut Lundby, 249-271. Berlin: Walter de Gruyter.

Hills, Matt. 2002. Fan cultures. London and New York: Routledge.

Horst, Heather A., Becky Herr-Stephenson, and Laura Robinson. 2009. Media ecologies. In Hanging out, messing around, and geeking out, eds. Mizuko Ito, Sonja Baumer, Matteo Bittani, danah boyd, et al., 29-78. Cambridge, MA: MIT University Press Group.

Hugger, Kai-Uwe. 2009. Junge Migranten online [Young immigrants online]. Wiesbaden: Springer.

Hull, Glynda A., and Katherine Schultz. 2002. School's out: Bridging out-of-school literacies with classroom practice. New York: Teachers College Press.

Hungerland, Beatrice, and Bernd Overwien. 2004. Kompetenzentwicklung im Wandel. Auf dem Weg zu einer informellen Lernkultur? Wiesbaden: VS Verlag für Sozialwissenschaften.

Illich, Ivan. 1971. Deschooling society. New York: Harper \& Row.

Ito, Mizuko, Sonja Baumer, Matteo Bittani, Danah Boyd, et al. 2009. Hanging out, messing around, and geeking out: Kids living and learning with new media. Cambridge, MA: MIT University Press Group.

Ito, Mizuko, Daisuke Okabe, and Izumi Tsuji. 2012. Fandom unbound: Otaku culture in a connected world. New Haven, CT: Yale University Press.

Ito, Mizuko, Kris Gutierrez, Sonia Livingstone, Bill Penuel, Jean Rhodes, Katie Salen, Juliet Schor, et al. 2013. Connected learning: An agenda for research and design. Digital media and learning research hub. Irvine, CA: BookBaby.

James, Nalita, and Hugh Busher. 2013. Researching hybrid learning communities in the digital age through educational ethnography. Ethnography and Education 8 (2): 194-209.

Jenkins, Henry. 2006. Fans, bloggers, and gamers: Exploring participatory culture. New York: New York University Press.

Jenkins, Henry, Ravi Purushotma, Margaret Weigel, Katie Clinton, and Alice J. Robison. 2009. Confronting the challenges of participatory culture: Media education for the 21st century. Cambridge, MA: MIT Press.

Jenkins, Henry, Mizuko Ito, and Danah Boyd. 2015. Participatory culture in a networked era: A conversation on youth, learning, commerce, and politics. Cambridge and Malden, MA: Wiley. 
Jörissen, Benjamin. 2007. Informelle Lernkulturen in Online-Communities. Mediale Rahmungen und rituelle Gestaltungsweisen. In Lernkulturen im Umbruch. Rituelle Praktiken in Schule, Medien, Familie und Jugend, eds. Christoph Wulf, Birgit Althans, Gerald Blaschke, Nino Ferrin, et al., 184219. Wiesbaden: VS Verlag für Sozialwissenschaften.

Kammerl, Rudolf. 2011. Schulische und außerschulische Sozialisation: Mediensozialisation in einer zunehmend mediatisierten Welt [School and extra-school socialisation. Media socialisation in an increasingly mediatized world]. In Sozialpsychologie, Sozialisation und Schule [Social psychology, socialisation, and school], ed. Erich H. Witte, Lutz-Michael Alisch, and Jörg Doll, 77-96. Lengerich: Pabst.

Keen, Andrew. 2007. The cult of the amateur: How blogs, MySpace, YouTube, and the rest of today's user-generated media are destroying our economy, our culture, and our values. New York: Doubleday.

Knowles, Malcolm S. 1975. Self-directed learning. A guide for learners and teachers. New York: Cambridge Books.

Koller, Hans-Christoph. 2011. The research of transformational education processes: Exemplary considerations on the relation of the philosophy of education and educational research. European Educational Research Journal 10 (3): 375-382.

Kop, Rita, Hélène Fournier, and Sui F.J. Mak. 2011. A pedagogy of abundance or a pedagogy to support human beings? Participant support on massive open online courses. The International Review of Research in Open and Distance Learning 12 (7): 74-93.

Krotz, Friedrich. 2007. Mediatisierung: Fallstudien zum Wandel von Kommunikation. Wiesbaden: VS Verlag für Sozialwissenschaften.

Lachmann, Richard. 1988. Graffiti as career and ideology. American Journal of Sociology 94 (2): 229-250.

Lane, Andy. 2009. The impact of openness on bridging educational digital divides. The International Review of Research in Open and Distributed Learning 10(5): 1-12. http://www.irrodl.org/index.php/irrodl/article/ view/637. Accessed 30 Mar 2017.

Lanier, Jaron. 2013. Who owns the future?. New York: Simon \& Schuster.

Lave, Jean. 1988. Cognition in practice: Mind, mathematics and culture in everyday life. Cambridge, New York: Cambridge University Press.

Lave, Jean. 2011. Apprenticeship in critical ethnographic practice. Chicago: University of Chicago Press.

Lave, Jean, and Etienne Wenger. 1991. Situated learning: Legitimate peripheral participation. Cambridge: Cambridge University Press.

Livingstone, David W. 1999. Exploring the icebergs of adult learning: Findings of the first Canadian survey of informal learning practices. Canadian Journal for the Study of Adult Education 13 (2): 49-72. 
Livingstone, David W. 2001. Adults' informal learning: Definitions, findings, gaps, and future research. NALL Working Paper \#21.

Luckin, R. 2010. Re-designing learning contexts: Technology-rich. Learner-centred Ecologies: Routledge.

Marsick, Victoria J., and Karen E. Watkins. 2001. Informal and incidental learning. New Directions for Adult and Continuing Education 89: 25-34.

Marsick, Victoria. J., Karen E. Watkins, and Barbara Lovin. 2011. Revisiting informal and incidental learning as a vehicle for professional learning and development. In Elaborating professionalism. Studies in practice and theory, ed. Clive Kanes, 59-76. Dordrecht: Springer.

McGaghie, W.C., S.B. Issenberg, E.R. Cohen, J.H. Barsuk, and D.B. Wayne. 2011. Does Simulation-based Medical Education with Deliberate Practice Yield Better Results than Traditional Clinical Education? A Meta-Analytic Comparative Review of the Evidence. Academic Medicine: Journal of the Association of American Medical Colleges 86 (6): 706-711. doi:10.1097/ ACM.0b013e318217el19.

Mieg, Harald A. 2008. Expertisierung vs. Professionalisierung: relative und andere Experten aus Sicht der psychologischen Expertiseforschung. In Die Natur der Gesellschaft (Verhandlungsband des 33. DGS-Kongresses), ed. KarlSiegbert Rehberg, 3265-3275. Frankfurt am Main: Campus.

Moravec, John W. 2013. Knowmad society: The "new" work and education. On the Horizon 21 (2): 79-83.

Peña-López, Ismael. 2013. Heavy switchers in translearning: From formal teaching to ubiquitous learning. On the Horizon 21 (2): 127-137.

Ponti, Marisa. 2014. Self-directed learning and guidance in non-formal open courses. Learning, Media and Technology 39 (2): 154-168.

Ragnedda, Massimo, and Glenn W. Muschert. 2013. The digital divide: The internet and social inequality in international perspective. Abingdon, NY: Routledge.

Ranieri, Maria, and Norbert Pachler. 2014. Inventing and re-inventing identity: Exploring the potential of mobile learning in adult education. Prospects 44 (1): 61-79.

Rogoff, Barbara. 2008. Observing sociocultural activity on three planes: Participatory appropriation, guided participation, and apprenticeship. In Pedagogy and practice: Culture and identities, ed. Kathy Hall, Patricia Murphy, and Janet Soler, 58-74. London: Sage.

Rogoff, Barbara E., and Jean E. Lave. 1984. Everyday cognition: Its development in social context. Cambridge MA, London: Harvard University Press.

Sargant, Naomi. 1991. Learning and „leisure": A study of adult participation in learning and its policy implications. Leicester: National Institute of Adult Continuing Education.

Sargant, N. 1993. Learning for a purpose: Participation in education and training by adults from the ethnic minorities. National Institute of Adult Continuing Education. 
Schnoor, Oliver, and Michaela Pfadenhauer. 2009. Kompetenzentwicklung in Jugendszenen. Das Karriere-Konzept als Zugang zur Rekonstruktion situierter Lernprozesse [Literacy development in youth scenes]. Zeitschrift für Qualitative. Forschung 10 (2): 293-320.

Schorb, Bernd, Thomas Rakebrand, and Nadine Jünger. 2013. Die Aneignung konvergenter Medienwelten durch Jugendliche: Das Medienkonvergenz Monitoring [Adolescents' appropriation of convergent media worlds: The media convergence monitoring]. Berlin: VISTAS.

Selwyn, Neil. 2013. Distrusting educational technology: Critical questions for changing times. Abingdon, NY: Routledge.

Siemens, George. 2005. Connectivism: Learning as network-creation. ASTD Learning News 10(1). http://www.itdl.org/journal/jan_05/article01.htm.

Simons, Robert-Jan. 2000. Various kinds of life long learning. In Lebenslanges Lernen im Beruf-seine Grundlegung im Kindes- und Jugendalter, ed. Frank Achtenhagen, and Wolfgang Lempert, 23-38. Wiesbaden: VS Verlag für Sozialwissenschaften.

Smith, Rochelle. 2010. Antislick to postslick: DIY books and youth culture then and now. The Journal of American Culture 33 (3): 207-216.

Spencer, Amy. 2008. DIY: The rise of lo-fi culture. London and New York: Marion Boyars Publishers.

Squire, Kurt. 2011. Video games and learning: Teaching and participatory culture in the digital age. Technology, education-connections (the TEC series). New York: Teachers College Press.

Tanenbaum, Joshua. G., Amanda M. Williams, Audrey Desjardins, and Karen Tanenbaum. 2013. Democratizing technology: Pleasure, utility and expressiveness in DIY and maker practice. Proceedings of the SIGCHI Conference on Human Factors in Computing Systems. ACM, 2603-2612.

Thomas, Doug, and John S. Brown. 2011. A new culture of learning: Cultivating the imagination for a world of constant change. Lexington, KY: CreateSpace Independent Publishing Platform.

Tough, Allen M. 1971. The adults' learning projects: A fresh approach to theory and practice in adult education. Toronto: Ontario Institute for Studies. In Education.

Tully, Claus. J. 2008. Alltagslernen in technisierten Welten: Kompetenzerwerb durch Computer, Internet und Handy [Everyday learning in technologized worlds: Competence development with computers, internet, and cellphones]. In Jugendliche in neuen Lernwelten [Adolescents in new learning worlds], ed. Peter Wahler, Claus J. Tully, and Christine Preiß, 165-199. Wiesbaden: Springer.

van de Wiel, Margje W.J., Piet van den Bossche, Richard P. Koopmans, Filip Dochy, David Gijbels, and Mien Segers. 2011. Deliberate practice, the high road to expertise. In Theories of learning for the workplace: Building blocks for training and professional development programs, ed. Filip Dochy, David 
Gijbels, Mien Segers, and Piet van den Bossche, 1-16. Abingdon, NY: Routledge.

Vygotsky, Lev S. 1980. Mind in society: The development of higher psychological processes. Cambridge, MA: Harvard University Press.

Wagner, Ulrike, Helga Theunert, Christa Gebel, and Bernd Schorb. 2012. Jugend und Information im Kontext gesellschaftlicher Mediatisierung. In Mediatisierte Welten, ed. Friedrich Krotz, and Andreas Hepp, 307-329. Wiesbaden: VS Verlag für Sozialwissenschaften.

Wenger, Etienne. 2001. Supporting communities of practice: A survey of community-oriented technologies. Report to the Council of CIOs of the US Federal Government. Available at https://guard.canberra.edu.au/opus/ copyright_register/repository/53/153/01_03_CP_technology_survey_v3.pdf.

Wenger, Etienne, Nancy White, and John D. Smith. 2009. Digital habitats: Stewarding technology for communities. Portland, OR: Cpsquare.

Wheeler, Steve. 2009. Learning space mashups: Combining Web 2.0 tools to create collaborative and reflective learning spaces. Future Internet 1(1): 3-13.

Wolf, Karsten D. 2006. Software für Online-Communities auswählen. In Handbuch E-Learning, ed. Andreas Hohenstein, and Karl Wilbers, 1-28. Köln: Fachverlag Deutscher Wirtschaftsdienst.

Wolf, Karsten D. 2012. The instructional design and motivational mechanisms of world of warcraft. In Computer games and new media cultures. A handbook of digital games studies, eds. Johannes Fromme and Alexander J. Unger, 557569. Dordrecht: Springer.

Wolf, Karsten D., and Andreas Breiter. 2014. Integration informeller und formaler Bildungsprozesse zur beruflichen Orientierung von Jugendlichen am Beispiel draufhaber.tv. In Lernen im Web 2.0-Erfabrungen aus Berufsbildung und Studium, eds. Nicole C. Krämer, Nicole Sträfling, Nils Malzahn, Tina Ganster, and Ulrich H. Hoppe, 85-101. Bielefeld: Bertelsmann.

Yee, Nick. 2017. "Beyond 50/50: Breaking Down The Percentage of Female Gamers By Genre." Quantic Foundry. http://quanticfoundry. com/2017/01/19/female-gamers-by-genre/. Accessed 23 Aug 2017.

Zawacki-Richter, Olaf. 2015. Zur Mediennutzung im Studium-unter besonderer Berücksichtigung heterogener Studierender [Media usage patterns in higher education]. Zeitschrift für Erziehungswissenschaft 18: 527-549.

Ziegler, Albert. 2012. Gifted education from a systemic perspective: The importance of educational capital and learning capital for the development of actiotopes. In Development of excellence in East-Asia: Explorations in the actiotope model of giftedness, ed. Shane N. Phillipson, Heidrun Stoeger, and Albert Ziegler, 18-39. London: Routledge. 
Open Access This chapter is licensed under the terms of the Creative Commons Attribution 4.0 International License (http://creativecommons.org/licenses/ by $/ 4.0 /)$, which permits use, sharing, adaptation, distribution and reproduction in any medium or format, as long as you give appropriate credit to the original author(s) and the source, provide a link to the Creative Commons license and indicate if changes were made.

The images or other third party material in this chapter are included in the chapter's Creative Commons license, unless indicated otherwise in a credit line to the material. If material is not included in the chapter's Creative Commons license and your intended use is not permitted by statutory regulation or exceeds the permitted use, you will need to obtain permission directly from the copyright holder.

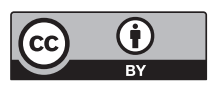

